МРНТИ 14.01.29

УДК 378.16:004.58

\title{
Г.Б. Камалова
}

https://doi.org/10.51889/2020-2.1728-7901.39

\section{Казахский национальный педагогический университет им. Абая, г. Алматы \\ САЙТ ОБРАЗОВАТЕЛЬНОГО КЛАСТЕРА КАК ИНСТРУМЕНТ ОТКРЫТОСТИ И ГЛАСНОСТИ ЕГО ДЕЯТЕЛЬНОСТИ}

\begin{abstract}
Аннотащия
Образовательные кластеры, объединяющие педагогические вузы, школы и бизнес, обеспечивают принципиально новое научно-образовательное пространство практико-ориентированной профессиональной подготовки будущих учителей и обучения школьников на базе современных облачных и дистанционных технологий. Несмотря на успешное функционирование, их деятельность до сих пор никак не отражена в глобальной сети и практически недоступна широкой общественности.

В статье обоснована необходимость разработки информационно-образовательного сайта кластера «школа педвуз - бизнес» для позиционирования его в сети Интернет с целью привлечения внимания общественности, обеспечения информационной открытости и прозрачности его деятельности. Представлена структура сайта, состав и содержание информационных материалов, публикуемых на его страницах, описаны требования, предъявляемые к контенту.
\end{abstract}

Ключевые слова: образовательный кластер, сайт, модульная структура сайта, мега-класс, мегаурок, контент.

Аңцдатпа

Г.Б. Камалова

Абай атындавы Қазақ ұлттық педагогикальқ университеті, Алматы к.

БІЛІМ БЕРУ КЛАСТЕРІНІН САЙТЫ ОНЫН ҚЫЗМЕТІНІН АШЫҚТЫҒЫ МЕН ЖАРИЯЛЫҒЫНЫН КҰРАЛЫ РЕТІНДЕ

Педагогигалық жоғары оқу орындарды, мектептерді және бизнесті біріктіретін білім беру кластерлер заманауи бұлтты және қашықтықтан оқыту технологияларының негізінде болашақ мұғалімдер мен мекткп оқушылары үшін практикалық-бағдарланған кәсіптік даярлау мұлдем жаңа ғылыми-білім беру кеңістігі болып табылады. Табысты жұмыс істегеніне қарамастан, олардың қызметі әлі күнге дейін жаһандық желіде көрінбейді және көпшілік үшін қол жетімді емес.

Мақалада қоғамның назарын аудару және оның ашықтығы мен ақпараттық ашықтығын қамтамасыз ету үшін «мектеп-педагогикалық университет-бизнес» кластерін ақпараттық және білім беру сайтын құру және оны Интернетте орналастыру қажеттілігі көрсетілген. Онда оның құрылымы, құрамы және өз беттерінде жарияланған ақпараттық материалдардың мазмұны, және мазмұнына қойылатын талаптар сипатталған.

Түйін сөздер: білім беру кластері, сайт, модульдік сайт құрылымы, мега-класс, мега-сабақ, сайт мазмұны

Abstract
WEBSITE OF EDUCATIONAL CLUSTER AS A TOOL
OF OPENNESS AND PUBLICITY OF HIS ACTIVITIES
Kamalova G.B.
Abai Kazakh National Pedagogical University, Almaty

Educational clusters, combining pedagogical universities, schools and business, provide an entirely new scientific and educational space of practice-oriented professional training of future teachers and schoolchildren based on modern cloud and distance technologies. Despite the successful functioning, their activity is still not reflected in the net and is practically inaccessible to the general public.

The article substantiates the need to develop an information and educational site for the educational cluster «school teacher training University - business» to position it on the Internet in order to attract public attention, to ensure information transparency and transparency of its activities. Its structure, composition and content of information materials published on its pages are given, the requirements for content are described.

Keywords: educational cluster, the site, the modular structure of the site, mega-class mega-lesson content

Высокая социокультурная значимость педагогического образования для устойчивого развития общества, необходимость повышения его качества с учетом современных требований актуализируют необходимость перехода на новую модель педагогического образования, интегрирующую педвузы с бизнес-структурами и со школьной средой для усиления практико-ориентированности подготовки 
будущих учителей, а также с другими педвузами для изучения и внедрения передового научнопедагогического опыта.

Сегодня в условиях цифровой трансформации образования, и работающему в школе учителю для успешной профессиональной деятельности также необходимо постоянное взаимодействие с коллегами, поэтому дистанционное общение, обмен опытом через сетевые профессиональные сообщества набирают свою актуальность, являясь ключевым условием построения инновационной среды обучения.

Наиболее перспективной в контексте изложенного является кластерная модель интеграции педагогических вузов друг с другом, с бизнес-структурами и со школьной средой, обеспечивающая на партнерских отношениях тесное взаимовыгодное сотрудничество между участниками кластера и предназначенная для решения общезначимых проблем, встречающихся в учебном процессе, таких как низкий уровень мотивации учащихся к обучению, неэффективное использование всех возможностей дистанционных образовательных технологий, оторванность от реальной практики и т.д.. А также для осуществления профессиональной подготовки будущих педагогов к работе в цифровой школе и повышения квалификации практикующих учителей [1-2].

Подобные образовательные кластеры в педагогическом образовании обеспечивают принципиально новое научно-образовательное пространство практико-ориентированной профессиональной подготовки будущих учителей и обучения школьников без коренной ломки их сложившихся укладов за счет преимуществ современных облачных и других Интернет-сервисов, дистанционных форм и средств обучения.

Сегодня, благодаря развитию сети Интернет и дистанционных образовательных технологий, имеется возможность расширить масштаб образовательного кластера до международного уровня с привлечением образовательных учреждений разных государств и весьма эффективно осуществлять сотрудничество не только в традиционных сферах деятельности, таких как совместное проведение конференций, обмен студентами и преподавателями, стажировки и т.п., позволяющих непосредственно познакомиться с образовательными системами других стран, обменяться научнопедагогическим опытом с зарубежными коллегами, но и в реальной повседневной научной и учебной деятельности, позволяющей развить навыки профессионального общения, приобрести бесценный опыт сотрудничества в международной академической среде, что обеспечит качественно новый уровень педагогического образования и ускорит процесс его интеграции в мировое образовательное пространство.

Весьма перспективной в кластерных моделях педагогического образования представляется технология Мега-класс, сущность которой заключается в объединении параллельных классов школ кластера в единый мега-класс, организации и проведении мега-уроков в этом мега-классе по учебным темам, представляющим общий для всех интерес, при участии учителей, преподавателей и студентов педагогического вуза, с привлечением ученых и специалистов различных бизнес-структур в режиме видеоконференцсвязи на базе облачных и дистанционных образовательных технологий [3-5]. Оригинальность данной технологии заключается в единовременном трехуровневом формате учебного процесса, обеспечивающем одновременное проведение классно-урочных занятий в школе, занятий по методической подготовке студентов в педвузе, консультационной деятельностью ученых и представителей бизнеса. При этом естественным способом в единый учебный процесс интегрируется подготовка будущего учителя нового поколения и его непрерывное профессиональное развитие в существующей системе педагогического образования. Сегодня это возможно благодаря развитию сети Интернет и дистанционных образовательных технологий.

Объединение педагогических вузов друг с другом, бизнес-структурами и со школами на основе платформы «Мега-класс» позволит не только установить тесную связь и партнерские отношения между образовательными учреждениями разных государств, но и предоставит возможность для вовлечения студентов в непрерывную профессионально-педагогическую деятельность в международной кластерной среде. Это позволит будущим педагогам быстро адаптироваться к педагогической деятельности и ее особенностям в условиях глобализации и всеобщей цифровизации образования, а также к современным требованиям, предъявляемым школой к их профессиональным качествам. Обеспечит непрерывное повышение квалификации практикующего учителя в процессе его непосредственной профессиональной деятельности, мотивированное и успешное обучение школьника за счет синергетических эффектов коллективного, межшкольного и статусного обучения в интегрированной учебной, научной и производственной среде школа-педвуз-бизнес.

Организационно-управленческая и образовательная деятельность в кластере, имеющем территориально удаленные подразделения, осуществляется в сети Интернет с использованием 
современных дистанционных технологий обучения в специальной информационно-образовательной среде с облачными и другими Интернет-сервисами. Уровень развития сети Интернет и дистанционных образовательных технологий сегодня позволяет это сделать.

Для обеспечения открытости и доступности информации о деятельности образовательного кластера, об особенностях организации обучения и контроля знаний обучающихся в кластере, о реализуемых программах и методиках, и в целом для формирования позитивного имиджа, образовательному кластеру целесообразно иметь свой официальный сайт. Позиционируя кластер в сети Интернет, он сделает его узнаваемым, позволит привлечь внимание общественности к его деятельности. Однако, несмотря на постоянный интерес ученых к проблеме повышения качества подготовки будущих учителей и значительное количество исследований в области их подготовки в рамках образовательного кластера [1-5], а также, несмотря на существование и успешное функционирование целого ряда педагогических кластеров, их деятельность никак не отражена в глобальной сети, и до сих пор нет разработанных сайтов. Более того, и вопросы создания сайта, как некоторой сетевой площадки для эффективной организации деятельности образовательного кластера, объединяющего педагогические вузы, школы и бизнес, и обеспечения ее открытости также до сих пор не были предметом отдельного исследования. Этим определяется актуальность рассматриваемой темы.

В любых организациях, имеющих территориально удаленные подразделения, каковым является и образовательный кластер, объединяющий педагогические вузы друг с другом, с бизнес-структурами и со школами, участникам необходимо работать с общими документами, принимать коллективные решения по тем или иным вопросам. Сегодня это возможно организовать в Интернете, создав в «облаке» виртуальную площадку, обладающую быстродействующим доступом и широким диапазоном разнообразных сервисов для совместной работы над планами мега-уроков и учебнометодическими материалами для их организации и проведения, а также для профессионального общения участников образовательного кластера друг с другом. Но это происходит только в рамках кластера и недоступно для широкой общественности. А современный образовательный кластер существует в открытом информационном пространстве, он может и должен быть интересен в нем и как своеобразное образовательное объединение, и в рамках конкретного педагогического опыта ее участников. И сайт позволит решить проблему обеспечения информационной открытости и прозрачности деятельности образовательного кластера, и может стать хорошим инструментом для более качественного и эффективного решения организации взаимодействия всех участников кластера друг с другом, информационной поддержки и мотивации обучения, индивидуальной помощи, информирования, организации различных дистанционных мероприятий и т.д.

Как следует из вышеизложенного, сайт образовательного кластера необходим и основополагающей целью его создания является позиционирование его в сети Интернет для оперативного и объективного информирования общественности о его деятельности, предоставление сетевой площадки для организации совместной работы, и возможности включения его в единое образовательное информационное пространство. Целевое назначение является ключевым фактором в определении вида сайта, его структуры и содержания информационных материалов, публикуемых на его страницах. Ясно, что для образовательного кластера «школа-педвуз-бизнес» наиболее целесообразен информационно-образовательный сайт с древовидной структурой с четко заданной иерархией страниц и полуоткрытый по доступности. Такая структура наиболее оптимальна и может максимально отвечать интересам его пользователей [6].

Для большего удобства работы с сайтом целесообразно, чтобы его архитектура имела модульную структуру, что позволит разрабатывать при необходимости новые модули и расширять их функциональность без кардинального изменения ранее созданных модулей. Модуль здесь понимается как часть информационной системы, автоматизирующая один или несколько процессов деятельности кластера, связанная с другими модулями единой тематикой и дополняющая их, но разрабатываемая таким образом, чтобы в случае своего изменения не затрагивать остальные.

Весь состав структурных модулей сайта «мега-класс», можно условно разделить на следующие группы.

Модуль интерфейса, который включает в себя авторизацию пользователей, поиск информации по сайту, фотогалерею, блок информационных сообщений, а также в обязательном порядке блок с общей информацией о деятельности образовательного кластера: его целях и задачах, участниках и контактных данных.

Базовые модули сайта представляют собой виртуальную площадку, отражающую непосредственную деятельность образовательного кластера с основными узлами выхода в облачные 
сервисы. Сюда включен модуль «Образовательный процесс» в кластере с множеством учебных дисциплин: информатика, математика, физика и др., каждая из которых, в свою очередь, включает разделы:

- «Обучение» с «календарным планом работ», «педагогической мастерской», представленной в виде вебинаров для учителей, где происходит обсуждение плана проводимых уроков и «электронной средой «мега-урок»»), в которой предоставлены все условия для «организации совместной работы учащихся» (ссылка на облако, ссылка на страницу в социальной сети для авторизованных пользователей) и, в которой проводятся «онлайн мега-уроки». Предполагается, что у всех субъектов кластера должна быть установлена программа видеоконференцсвязи типа ZOOM, на сайте предоставляется лишь информация, как войти в виртуальный зал: идентификатор конференции и пароль. Вход в педагогическую мастерскую предоставляется только авторизованным пользователям, а на мега-уроки вход свободный для всех желающих.

- «Методическая копилка», представленная в виде базы данных с проектными заданиями, «живыми», практико-ориентированными задачами и сценариями уроков по разным темам [5]. Доступ к ним может быть свободный, для всех интересующихся образовательной деятельностью в кластере.

- Здесь же имеется «предметный форум».

Немаловажное значение для организации деятельности в кластере имеет модуль с условным названием «Еще...», включающим:

- «Публикации», интересные с точки зрения организации деятельности образовательного кластера, организации и проведения мега-уроков, представленные в виде ссылок на Интернет-источники, и, написанных участниками кластера монографий, учебно-методических пособий, всевозможных инструкций и методических рекомендаций.

- «Современные инструменты - помощники педагога» со ссылками на Интернет-ресурсы, а также

- «Шаблоны» с готовыми формами дипломов, сертификатов и благодарностей для награждения активных участников мега-уроков.

Как видно, наряду с информационными блоками, представленными на сайте, вся образовательная деятельность кластера, в числе которых организация и проведение:

- обучающих семинаров, мастер-классов, семинаров-обсуждений сценариев мега-уроков при подготовке к ним;

- онлайн мега-уроков; видеоконференций; сетевых проектов и конкурсов;

- обсуждение в чате, форуме и т.д.

прозрачна и большая часть из них открыта для общественности в соответствии с основополагающей целью создания сайта.

Одной из важных структурных составляющих образовательного кластера является международная научная лаборатория, основной задачей деятельности которой является осуществление научноисследовательской работы в целях развития теории и практики электронного обучения; разработки основанных на ИКТ современных образовательных технологий и дидактических моделей, а также организации взаимодействия образовательного кластера с ведущими зарубежными научными центрами в целях проведения совместных научных исследований и реализации образовательных проектов. Лаборатория является неким образовательным инкубатором по проектированию среды «живых», практико-ориентированных задач, используемых на мега-уроках, на нее возлагается координация деятельности кластера в целом. Кроме этого, в ее функции входит и администрирование его сайта.

Для представления актуальной информации о ее деятельности на сайте образовательной кластерной платформы «Мега-класс» необходимо создание специального модуля «Международная научная лаборатория〉 со всеми нормативно-правовыми документами, регламентирующими ее деятельность, планами и результатами проводимых ею фундаментальных и прикладных исследований, а также «Службой технического и методического сопровождения мега-уроков» с инструкциями по организации и проведению мега-уроков и необходимыми контактными данными.

Для обеспечения результативной деятельности образовательного кластера в сети, удобства работы пользователей сайт должен иметь интуитивно понятный интерфейс; должна быть предусмотрена возможность оставлять комментарий, подключаться к обсуждению в форуме; и, при желании, подключаться к работе и стать участником кластера.

Вышеописанная структура сайта образовательного кластера «школа-педвуз-бизнес», оформлена в информационном интеграторе «Иерархия-2000» [7] и представлена рис.1. 


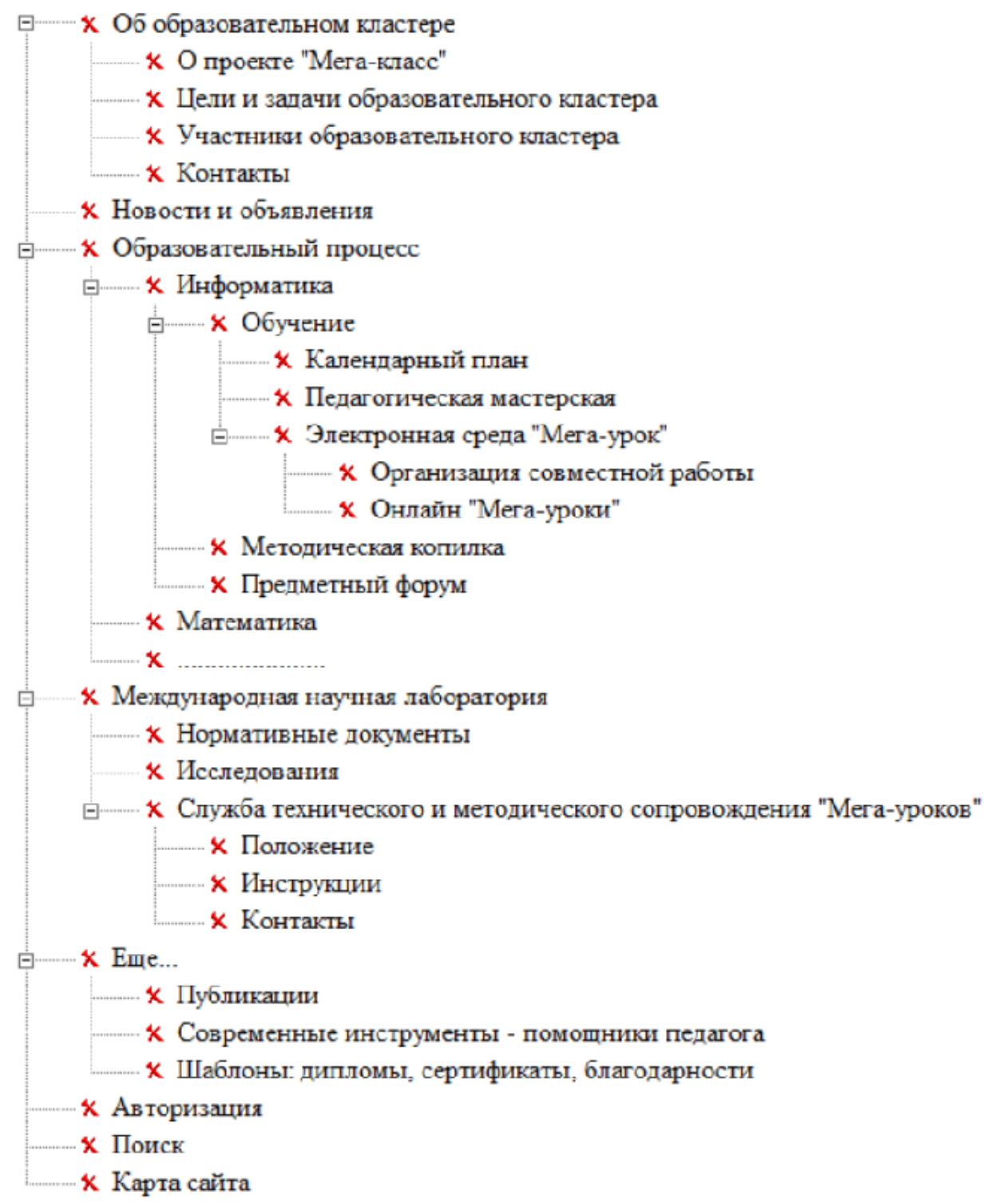

Рисунок 1. Структура сайта образовательного кластера «икола-педвуз-бизнес»

Одним из ключевых элементов сайта является его информационное наполнение (контент). Он служит основным средством освещения деятельности образовательного кластера и привлечения к нему внимания общественности. Контент сайта должен быть хорошо структурированным, оперативно обновляемым, информативным, интересным и легальным.

Он должен соответствовать тематическому разделу сайта и основной цели его создания. Язык изложения должен быть четким, лаконичным, грамотным, убедительным. Применяемая терминология должна соответствовать педагогическому тезаурусу. Правильный его подбор и администрирование определяют в целом успешное функционирование сайта в соответствии с целями его создания. Ответственность за информационное наполнение сайта несет модератор, один из членов научной лаборатории.

Администрирование информационно-образовательного сайта «мега-класс» осуществляется также членом научной лаборатории. Он обеспечивает бесперебойную работу сайта, своевременно размещая необходимую информацию и обеспечивая регулярное её обновление. Отвечает за включение в структуру сайта дополнительных модулей и новых сервисов.

Подобные сайты служат не просто интернет-площадкой для разворачивания деятельности образовательного кластера в сети, но и станут его визитной карточкой, и обеспечат информационную открытость и прозрачность всей его деятельности.

Статья подготовлена при финансовой поддержке проекта МОН РК №AР05133502 
Список использованной литературы:

1 Бидайбеков Е.Ы., Камалова Г.Б., Пак Н.И., Аккасынова Ж.К. Совершенствование профессиональной подготовки будущего учителя информатики на основе кластерной модели обучения // Вестник КазНПУ имени Абая. Серия «Физико-математические науки». - Алматы, 2015. - №2(50). - C. 205-211.

2 Камалова Г.Б., Киселева Е.А. К вопросу подготовки педагогов в условиях глобализации // Вестник КазНПУ имени Абая. Серия «Физико-математические науки». - Алматы, 2018. - №3(63). - C. $364-370$

3 Ивкина Л.М. Формирование методической готовности будущих учителей информатики в условиях образовательной платформы «Мега-класс»» / Дис. ... канд. пед. наук: 13.00.02 / Красноярский государственный университет им. В.П. Астафьева. - Красноярск, 2017. - 145 с.

4 Пак Н.И., Сокольская М.А. Единая методическая система предметного обучения икольников и студентов на базе технологической платформы «Мега-класс». - С. 124-134.

5 Ивкина И.М., Кулакова И.А., Пак Н.И., Романов Д.В., Симонова А.Л., Сокольская М.А., Хегай Л.Б., Яковлева Т.А. Мега класс как инновачионная модель обучения информатике с использованием ДОТ и СПО: коллективная монография / Краснояр. гос. пед. ун-т им. В.П. Астафьева. - Красноярск, 2014. - 195с.

6 Структура сайта: разработка структуры в виде схемы, типы и примеры [Электронный ресурс]. URL: https://postium.ru/struktura-sajta-razrabotka-v-vide-sxemy/_(дата обращения: 05.06.2020)

7 Григорьев С.Г., Гриншкун В.В., Макаров С.И. Методико-технологические основы создания электронных средств обучения. - Самара: Самарская государственная экономическая академия, 2002. - 110с.

\section{References:}

1 Bidajbekov E.Y., Kamalova G.B., Pak N.I., Akkasynova Zh.K. (2015) Sovershenstvovanie professional'noj podgotovki budushhego uchitelja informatiki na osnove klasternoj modeli obuchenija Vestnik KazNPU imeni Abaja. Serija «Fiziko-matematicheskie nauki». Almaty, 205-211.

2 Kamalova G.B., Kiseleva E.A. (2018) K voprosu podgotovki pedagogov v uslovijah globalizacii Vestnik KazNPU imeni Abaja. Serija «Fiziko-matematicheskie nauki». Almaty, 364-370.

3 Ivkina L.M. (2017) Formirovanie metodicheskoj gotovnosti budushhih uchitelej informatiki $v$ uslovijah obrazovatel'noj platformy «Mega-klass» Dis. kand. ped. nauk: 13.00.02 Krasnojarskij gosudarstvennyj universitet im. V.P. Astaf'eva. Krasnojarsk, 145.

4 Pak N.I., Sokol'skaja M.A. Edinaja metodicheskaja sistema predmetnogo obuchenija shkol'nikov i studentov na baze tehnologicheskoj platformy «Mega-klass». 124-134.

5 Ivkina I.M., Kulakova I.A., Pak N.I., Romanov D.V., Simonova A.L., Sokol'skaja M.A., Hegaj L.B., Jakovleva T.A. (2014) Mega klass kak innovacionnaja model' obuchenija informatike s ispol'zovaniem DOT i SPO: kollektivnaja monografija Krasnojar. gos. ped. un-t im. V.P. Astaf'eva. Krasnojarsk, 195.

6 Struktura sajta: razrabotka struktury $v$ vide shemy, tipy $i$ primery [Jelektronnyj resurs]. URL: https://postium.ru/struktura-sajta-razrabotka-v-vide-sxemy/(data obrashhenija: 05.06.2020)

7 Grigor'ev S.G., Grinshkun V.V., Makarov S.I.(2002) Metodiko-tehnologicheskie osnovy sozdanija jelektronnyh sredstv obuchenija. Samara: Samarskaja gosudarstvennaja jekonomicheskaja akademija, 110. 